Article

\title{
Preparation and Characterization of Polyurethanes with Cross-Linked Siloxane in the Side Chain by Sol-Gel Reactions
}

\author{
Hui Zhao ${ }^{1}$, Tong-Hui Hao ${ }^{1}$, Guo-Hua Hu ${ }^{2}$, Dean Shi ${ }^{1}$, Da Huang ${ }^{1}$, Tao Jiang ${ }^{1}$ and \\ Qun-Chao Zhang ${ }^{1, *}$ \\ 1 Hubei Collaborative Innovation Center for Advanced Organic Chemical Materials, \\ Ministry of Education Key Laboratory of Green Preparation and Application for Functional Materials, \\ School of Materials Science \& Engineering, Hubei University, Wuhan 430062, China; \\ zhh0625@foxmail.com (H.Z.); haoth@hubu.edu.cn (T.-H.H.); deanshi2012@yahoo.com (D.S.), \\ ganminzhao@163.com (D.H.); jiangtao@hubu.edu.cn (T.J.) \\ 2 Laboratory of Reactions and Process Engineering, CNRS-University of Lorraine, 1 rue Grandville, BP 20451, \\ Nancy CEDEX 54001, France; guo-hua.hu@univ-lorraine.fr \\ * Correspondence: zhangqc1976@hubu.edu.cn; Tel.: +86-158-7128-3888 \\ Academic Editor: Silvia Gross \\ Received: 13 December 2016; Accepted: 25 February 2017; Published: 28 February 2017
}

\begin{abstract}
A series of novel polyurethanes containing cross-linked siloxane in the side chain (SPU) were successfully synthesized through a sol-gel process. The SPU was composed of $0 \%-20 \% \mathrm{~N}$-(n-butyl)-3aminopropyltriethoxysilane (HDI-T) modified hexamethylene diisocynate homopolymer. The effects of HDI-T content on both the structure and properties of SPU were investigated by Fourier transform infrared spectroscopy (FT-IR), X-ray photoelectron spectroscopy (XPS), X-ray diffraction (XRD), scanning electron microscopy (SEM), energy dispersive spectroscopy (EDS), differential scanning calorimetry (DSC), thermogravimetric analysis (TGA), mechanical properties tests, gel content test, water contact angle measurement and water absorption test. FT-IR, XPS and XRD results confirmed the successful incorporation of HDI-T onto polyurethanes and the formation of $\mathrm{Si}-\mathrm{O}-\mathrm{Si}$. The surface roughness and the Si content of SPU enhanced with the increase of HDI-T content. Both crystallization and melting temperature shifted to a lower point after the incorporation of HDI-T. The hydrophobicity, tensile strength, Young's modulus and pencil hardness overall increased with the increasing of HDI-T content, whereas the thermal stability and the elongation at break of SPU slightly decreased.
\end{abstract}

Keywords: cross-linked; polysiloxane; polyurethane; micromorphology

\section{Introduction}

Polyurethanes (PUs) are used in numerous applications such as coatings, adhesives, fibers, foams, rubbers, thermoplastic elastomers and composites [1-7]. It is the flexibility in selection of monomers from a great variety of diisocyanates, polyester and chain extenders, as well as the ability to form different types of molecular architectures that provide PUs with many excellent properties such as toughness, abrasion resistance, mechanical properties and chemical resistance [8-12].

However, there is still a need to improve properties of PUs with the emphasis on their hydrophobicity and mechanical properties. This can be achieved by varying the microstructures of PUs or incorporating inorganic fillers. For example, organic-inorganic nanocomposites were developed to combine the desirable properties of PUs and those of inorganic fillers [13-16] such as clay, silica and other nano-sized layered silicates. Consequently, significant improvement in performances such as mechanical properties, thermal stability and others was achieved. Moreover, various PU/polysiloxane hybrids, PU/alkoxysilane hybrids, PU/acrylic hybrids, PU/epoxy resin hybrids, were prepared to offer 
synergetic proprieties through different methods, such as ultraviolet polymerization, miniemulsion polymerization, seeded emulsion polymerization and interpenetrating polymer networks [17-20].

Among the above methods, modification of PUs with polysiloxane is an important and effective way to prepare high performance materials [21]. The unique properties of polysiloxane, such as low surface energy, good thermal stability, and excellent flexibility, are mainly attributed to its intrinsic structure contained inorganic $\mathrm{Si}-\mathrm{O}$ bonds. The combination of $\mathrm{PU}$ and polysiloxane could offer a better heat resistance and low temperature flexibility than PU alone and better mechanical properties and abrasion characteristics than polysiloxane alone [22-24]. Therefore, the possibility of combining the advantages of polysiloxane and PU has triggered many investigations for a long time.

Most methods for improving water resistance, surface hydrophilicity and mechanical strength of PU are to introduce siloxane at both ends of the PU chain [25-35], as shown in Figure 1. The entrained Si-O- $\mathrm{R}$ will ensure the cross-linking of the modified PU, which may improve its water resistance, surface hydrophilicity and mechanical properties. However, the siloxane can only be introduced at the terminal groups of the backbone. Therefore, the amount of cross-linked units is low and consequently the improvement in the properties of PU may not be significant enough.

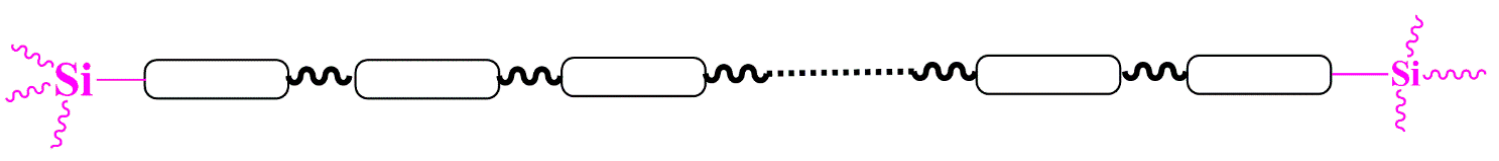

Figure 1. Modification of PU backbone with siloxane.

This work aims to attach siloxane onto both the backbone and side chains of PU, as shown in Figure 2. In this way, the amount of siloxane in PU would increase greatly, which may further significantly improve the surface hydrophilicity and mechanical properties.

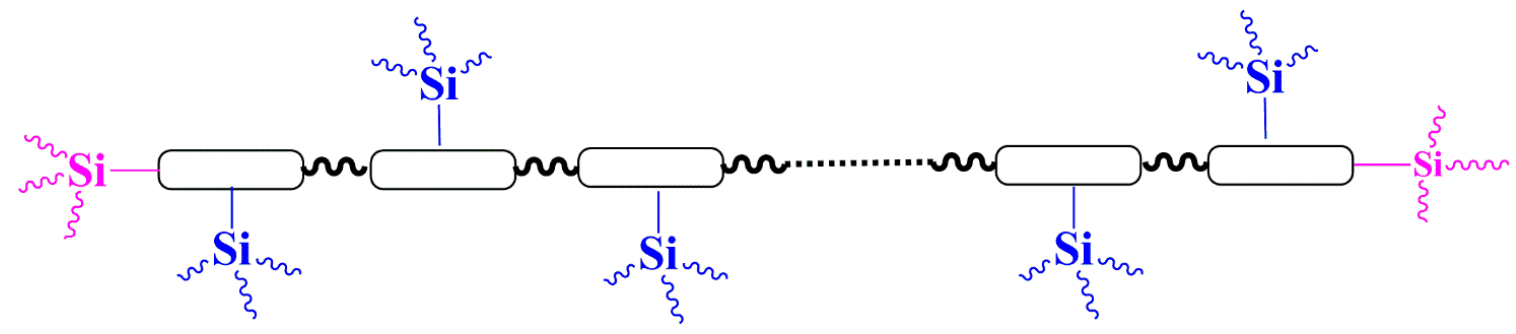

Figure 2. PU modified with siloxane in both backbone and side chains.

Firstly, hexamethylene diisocyanate homopolymer (HDI-3) was grafted with $N$-(n-butyl)-3aminopropyltriethoxysilane (NBAPTS) to generate HDI-T. A given amount of HDI-T was then mixed with 1,6-hexamethylene diisocyanate (HDI). The mixture reacted with polytetramethylene glycol (PTMG). The resulting product was chain-extended with 1,4-butanediol (BDO) and blocked with NBAPTS. This process offers a novel self-designing approach to develop novel PU with excellent properties. The structure and properties of the resultant materials were investigated by Fourier transform infrared spectroscopy (FT-IR), X-ray photoelectron spectroscopy (XPS), X-ray diffraction (XRD), scanning electron microscope (SEM), differential scanning calorimetry (DSC), thermogravimetric analysis (TGA), and mechanical and gel content tests.

\section{Materials and Methods}

\subsection{Materials}

1,6-hexamethylene diisocyanate (HDI), hexamethylene diisocyanate homopolymer (HDI-3), and polytetramethylene glycol (PTMG; number-average molecular weight $M_{\mathrm{n}}$ of $2000 \mathrm{~g} / \mathrm{mol}$ were obtained 
from Bayer Material Science (Pittsburgh, PA, USA). N-butyl-3-ammonia propyl triethoxy silane (NBATPS) was of analytical purity and obtained from Hubei Diamond Advanced Material of Chemical, Inc. (Yingcheng, China). Dibutylamine, sodium bicarbonate, tetrahydrofuran (THF) and 1,4-butanediol (BDO) were analytical reagents and obtained from Sinopharm Chemical Reagent Co., Ltd. (Shanghai, China). Both PTMG and THF were dehydrated before use.

\subsection{Experiments}

\subsubsection{Preparation of HDI-3 Grafted NBATPS}

As shown in Figure 3, NBAPTS (13.85 g) and HDI-3 (27.39 g, $-\mathrm{NCO}=23 \%)$ were added to anhydrous THF (41.24 g) in a $500 \mathrm{~mL}$ four-neck round-bottom flask filled with argon and equipped with a mechanical stirrer. Experiments were performed at $0{ }^{\circ} \mathrm{C}$ and the rotation speed of the mechanical stirrer was $300 \mathrm{rpm}$. The dibutylamine method was used to determine the content of the isocyanate groups in the reaction system. The reaction was stopped when the content of the isocyanate groups reached a theoretical value $(-\mathrm{NCO}=5.09 \%)$ and the target HDI-T was obtained.

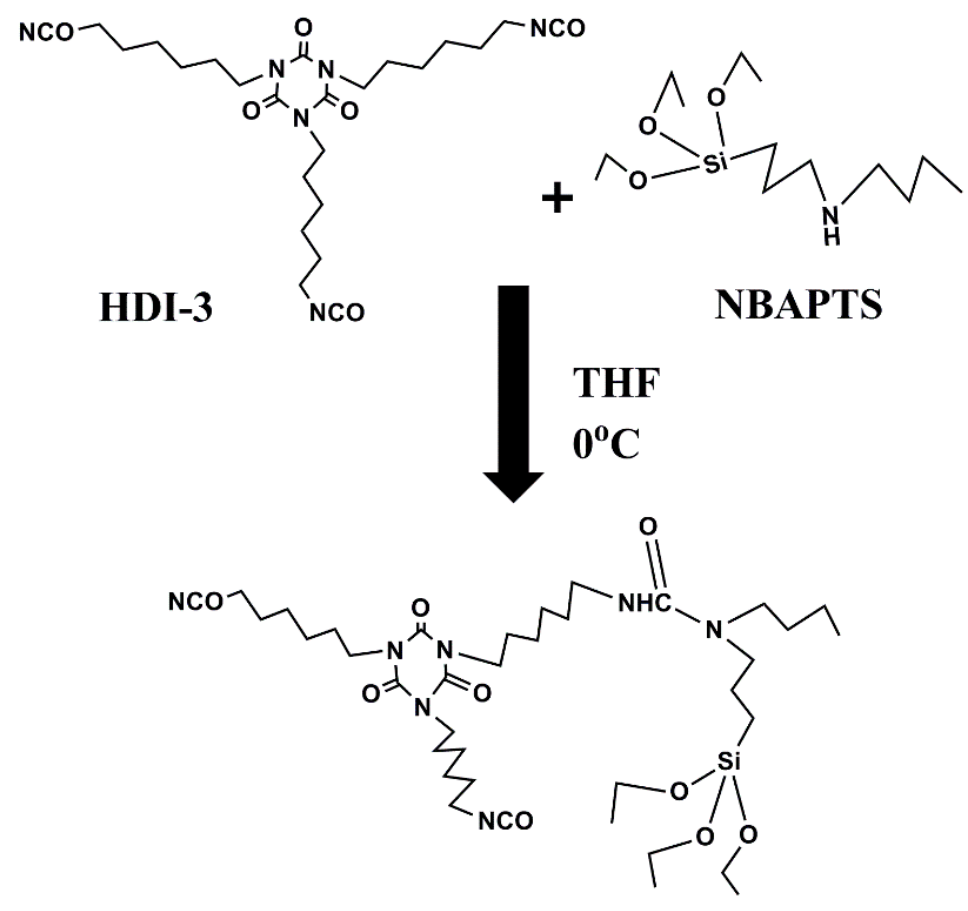

HDI-T

Figure 3. Preparation of HDI-T.

\subsubsection{Synthesis of Silicone/Polyurethane (SPU) Hybrids}

As shown in Figure 4, the molar ratio between isocyanate and hydroxyl groups was fixed at 1.2. THF, PTMG, HDI and HDI-T were added to a four-neck round-bottom filled with argon. The mixture was maintained at $25^{\circ} \mathrm{C}$ and stirred for $30 \mathrm{~min}$. Two drops of dibutyltin dilaurate (DBTDL) as a catalyst was added and the mixture was heated up to $55^{\circ} \mathrm{C}$ and was maintained at that temperature until the theoretical $-\mathrm{NCO}$ value was reached. The resulting prepolymer was chain-extended with $\mathrm{BDO}$ at $45^{\circ} \mathrm{C}$. After the flask was cooled to room temperature, NBATPS was added dropwise to the flask at 20 drops per minute until the isocyanate groups were used up. Finally, a homogeneous and transparent SPU hybrid was obtained. The compositions of all samples are given in Table 1. 


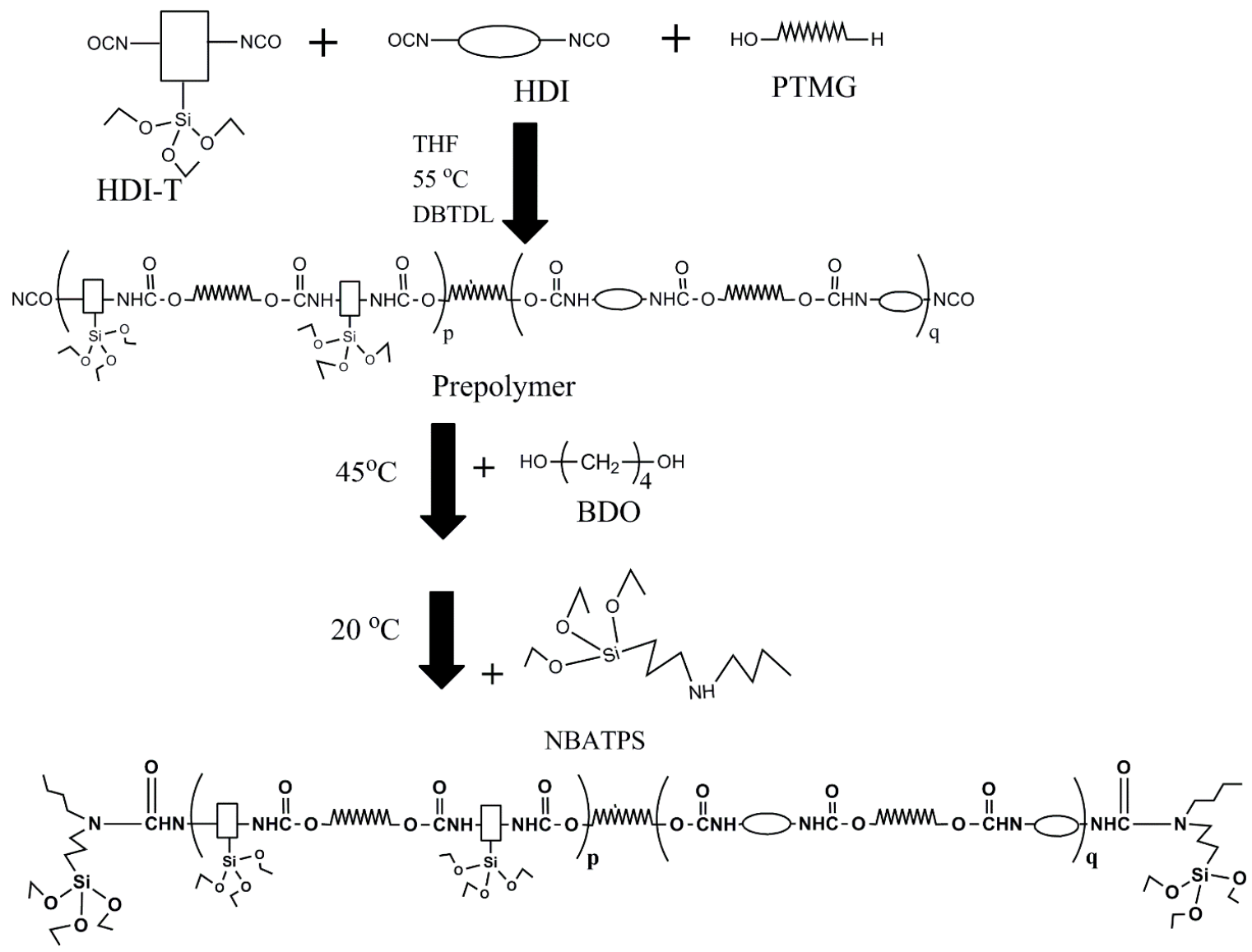

Figure 4. Preparation of SPU hybrids.

Table 1. Compositions for the synthesis of SPU hybrids.

\begin{tabular}{cccccc}
\hline Samples & HDI (mol) & HDI-T (mol) & PTMG (mol) & BDO (mol) & NBAPTS (mol) \\
\hline SPU0 & 0.0480 & 0 & 0.02 & 0.02 & 0.016 \\
SPU5 & 0.0456 & 0.0024 & 0.02 & 0.02 & 0.016 \\
SPU10 & 0.0432 & 0.0048 & 0.02 & 0.02 & 0.016 \\
SPU15 & 0.0408 & 0.0072 & 0.02 & 0.02 & 0.016 \\
SPU20 & 0.0384 & 0.0096 & 0.02 & 0.02 & 0.016 \\
\hline
\end{tabular}

\subsubsection{Preparation of Silicone/Polyurethane (SPU) Films}

All hybrids obtained in Section 2.2.2 were smeared evenly on a polytetrafluoroethylene mold at room temperature for 7 days for moisture-induced curing and a series of cross-linked SPU films were obtained, as shown in Figure 5. 


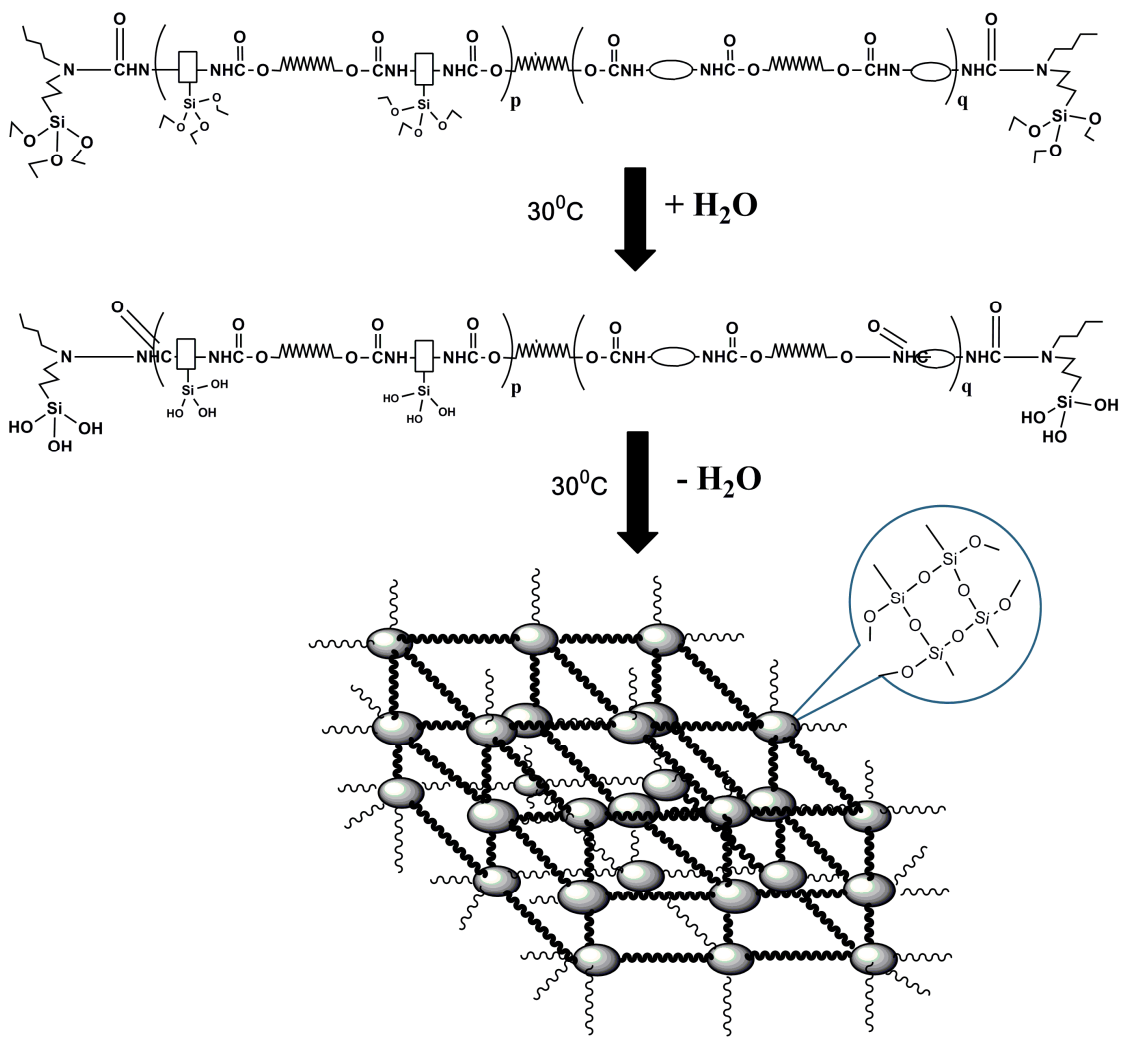

Figure 5. Preparation of SPU films.

\subsection{Characterization}

FT-IR spectroscopy analysis: FT-IR spectroscopy was performed on a spectrometer (Thermo Fisher Scientific, Waltham, MA, USA) using the attenuated total reflectance technique. Data were collected in the range of $4000-500 \mathrm{~cm}^{-1}$ at $4 \mathrm{~cm}^{-1}$ resolution.

XPS analysis: X-ray photoelectron spectroscopy (XPS) measurements were made on a Thermo VG ESCALAB 250 spectrometer (East Grinstead, UK) with a monochromatic Al-K $\alpha$ X-ray source.

Differential Scanning Calorimetry (DSC) analysis: Between 5 and $10 \mathrm{mg}$ pre-dried samples were analyzed by a DSC equipment (Q200, Newcastle, TA, USA). Samples were heated up from 30 to $100^{\circ} \mathrm{C}$ at a rate of $20^{\circ} \mathrm{C} \cdot \mathrm{min}^{-1}$ and held at $100{ }^{\circ} \mathrm{C}$ for $3 \mathrm{~min}$ to remove the thermal history under a dry helium purge. They were then cooled down to $-50{ }^{\circ} \mathrm{C}$ at a rate of $20^{\circ} \mathrm{C} \cdot \mathrm{min}^{-1}$. Finally, they were heated up to $100{ }^{\circ} \mathrm{C}$ again at the same rate.

Wide angle XRD analysis: Wide angle $X$-ray diffraction measurement was carried out with a Philips X'pert-PRO (PANalytical, Holland) using $\mathrm{Cu}-\mathrm{K} \alpha$ radiation. The diffraction angle $2 \theta$ ranged from $5^{\circ}$ to $60^{\circ}$.

Surface morphology analysis: The surface morphology of the SPU samples was analyzed by scanning electron microscopy (SEM, JSM5900LV, JEOL, Tokyo, Japan) at an accelerating voltage of $25 \mathrm{kV}$. Samples were adhered to aluminum sample holders and sputter coated with Au layer. The content of Si element on the surface of SPU films was measured by energy dispersive spectroscopy (EDS, EMAX, and EX-450 JEOL, Tokyo, Japan).

Thermogravimeter analysis (TGA): TGA was used to measure the weight loss of the SPU films under nitrogen atmosphere. Samples were heated from 100 to $700{ }^{\circ} \mathrm{C}$ at a heating rate of $10{ }^{\circ} \mathrm{C} \cdot \mathrm{min}^{-1}$.

Mechanical properties analysis: The tensile properties of the films were measured at $25^{\circ} \mathrm{C}$ with a universal testing machine (CMT, SANS, Shenzhen Sans Material Test Instrument Co., Ltd., Shenzhen, China) at a crosshead speed of $300 \mathrm{~mm} \cdot \mathrm{min}^{-1}$. The reported values were averages of five specimens. 
Pencil hardness was carried out by a pencil according to ISO 15184. The SPU were coated on a glass and the final thickness of the films was about $100 \mu \mathrm{m}$.

Gel contents analysis: Samples (approximately $1 \mathrm{~g}$ ) were cut from the SPU films, weighed, and then put in a Soxhlet extractor (Wuhan, China) filled with THF for $24 \mathrm{~h}$. After the extraction, the samples were dried, the gel contents $W_{\mathrm{g}}(\%)$, were calculated as

$$
W_{\mathrm{g}}(\%)=m_{2} / m_{1} \times 100 \% .
$$

where $m_{1}$ and $m_{2}$ are the masses of dried SPU films before and after the extraction, respectively.

Water contact angle analysis: Water contact angles (WCA) were measured through the sessile drop method on Dataphysics OCA20 (Wuhan, China) contact angle meter. The reported WCA values were the averages of five measurements taken at five different surface locations.

Water absorption analysis: Two grams of pre-weighed dry SPU films were immersed in de-ionized water at room temperature. After the excess water was wiped from the film surface by filter paper, the mass of the swollen film was measured immediately. The water absorption was calculated as the mass percentage of water in the swollen sample as:

$$
\text { Water absorption }=\left(m_{3}-m_{4}\right) / m_{4} \times 100 \%
$$

where $m_{4}$ and $m_{3}$ are the masses of the dry and swollen samples, respectively.

\section{Results and Discussion}

\subsection{Infrared Spectroscopy}

A series of SPU hybrids and films were synthesized on the basis of the HDI-T and NBATPS. Stable hybrids and films were obtained by the addition of $0,5,10,15$ and $20 \mathrm{~mol} \%$ HDI-T to SPU, respectively. The FT-IR spectra of the SPU films are shown in Figure 6. The weak absorption bands around $3310 \mathrm{~cm}^{-1}$ (N-H stretching) and $1530 \mathrm{~cm}^{-1}$ (N-H bending) and strong absorptions at $1700 \mathrm{~cm}^{-1}$ (free $\mathrm{C}=\mathrm{O}$ stretching of urethane and carboxylic groups) and $1210-1240 \mathrm{~cm}^{-1}$ (stretching vibration of $\mathrm{N}-\mathrm{CO}-\mathrm{O}$ ) confirm the formation of the urethane linkage. The peaks at 2938,2857 , and $2800 \mathrm{~cm}^{-1}$ $\left(\mathrm{CH}_{2}\right.$ and $\mathrm{CH}_{3}$ stretching vibration); $1105 \mathrm{~cm}^{-1}$ (C-O-C stretching vibration of PTMG and Si-O-Si asymmetric stretching vibration); $1258 \mathrm{~cm}^{-1}\left(\mathrm{CH}_{3}-\right.$ in Si- $\mathrm{CH}_{3}$ symmetric bending), 1072 and $1021 \mathrm{~cm}^{-1}$ (Si-O stretching); and $800 \mathrm{~cm}^{-1}$ (Si-C stretching) can clearly be observed in the spectra. The peak at $2270 \mathrm{~cm}^{-1}$ ( $\mathrm{N}=\mathrm{C}=\mathrm{O}$ stretching) has disappeared. This indicates that siloxane groups were successfully introduced into the SPU hybrid films.

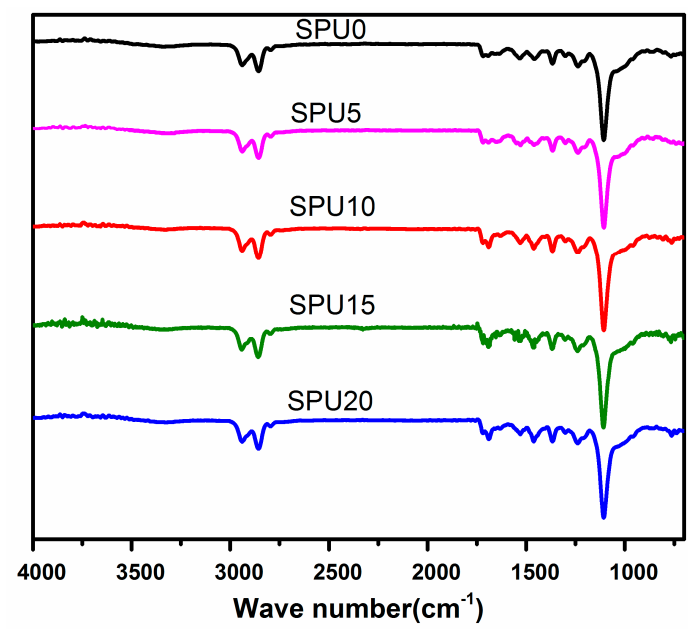

Figure 6. FT-IR of different SPU films. 


\subsection{XPS Analysis of SPU Films}

The XPS survey spectra of all samples reveal the characteristic signals of carbon (C 1s), nitrogen $(\mathrm{N} 1 \mathrm{~s})$ and oxygen $(\mathrm{O} 1 \mathrm{~s})$ at about $285 \mathrm{eV}, 400 \mathrm{eV}$ and $533 \mathrm{eV}$, respectively. The existence of additional signals of silicon ( $\mathrm{Si} 2 \mathrm{p}$ at about $102 \mathrm{eV}$ and $\mathrm{Si} 2 \mathrm{~s}$ at about $153 \mathrm{eV}$ ) indicates the incorporation of $\mathrm{Si}$ element. Figure 7 shows the XPS spectra of Si $2 p$ on the surface of sample SPU15. The peaks at $101.95 \mathrm{eV}$ and $102.6 \mathrm{eV}$ are the binding energies of $\mathrm{Si}-\mathrm{O}-\mathrm{Si}$ and $\mathrm{Si}-\mathrm{O}-\mathrm{C}$, respectively. The $\mathrm{Si}-\mathrm{O}-\mathrm{C}$ bond corresponds to triethoxysilane groups, which have survived during the film formation. The $\mathrm{Si}-\mathrm{O}-\mathrm{Si}$ bond proves the formation of the network by the condensation of the trialkoxysilane.
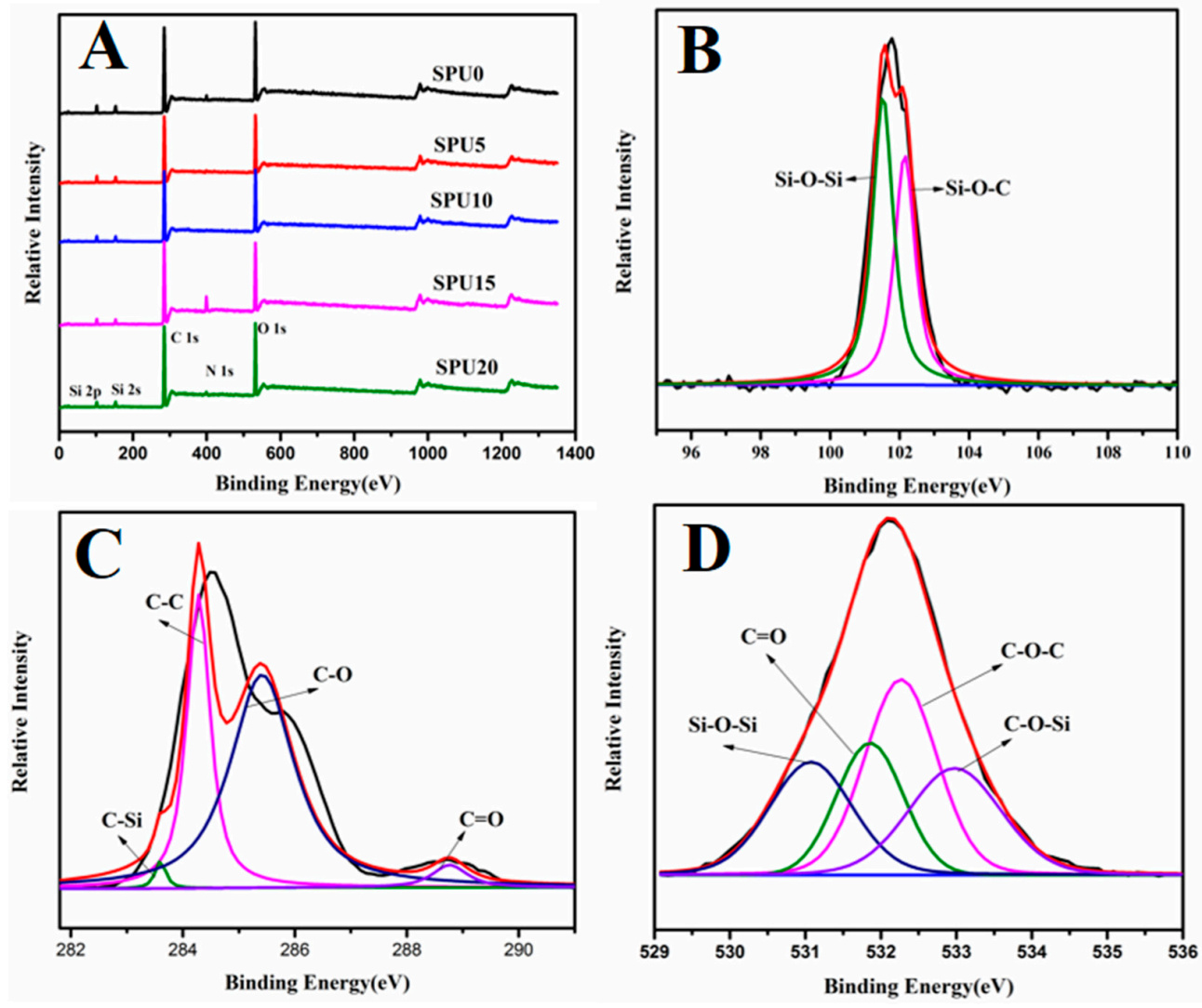

Figure 7. XPS spectra: (A) survey spectrum of different SPU films; (B) Si 2p of SPU15 film; (C) C 1s of SPU15 film; and (D) O 1s of SPU15 film.

\subsection{DSC Analysis of SPU Films}

DSC results showed that the crystallization temperatures of SPU0, SPU5, SPU10, SPU15 and SPU20 were $-22.4,-23.9,-25.4,-31.1$, and $-31.5^{\circ} \mathrm{C}$, respectively. Their melting temperatures were 29.1, 26.3, 25.7, 23.7, and $19.7^{\circ} \mathrm{C}$, respectively, as shown in Figure 8 and Table 2. The chemical linkages as a result of the polycondensation reaction between $-\mathrm{S}-\mathrm{O}-\mathrm{C}_{2} \mathrm{H}_{5}$ and $\mathrm{H}_{2} \mathrm{O}$ might have weakened the crystallization ability of the soft segments [36,37], decreased the melting temperature of the crystalline domains, and also restricted the movement of the molecular chains in the crystallized domains even at temperatures above the melting temperature, and provided the SPU films with an elastomer state at ambient temperature. This result indicated that the addition of HDI-T affected the crystal structure of the polymer and resulted in a lower crystallinity or lower degree of segment order. 


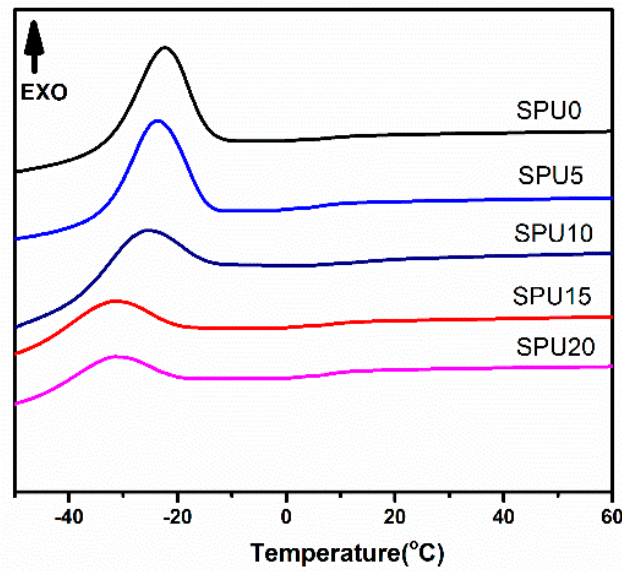

(a)

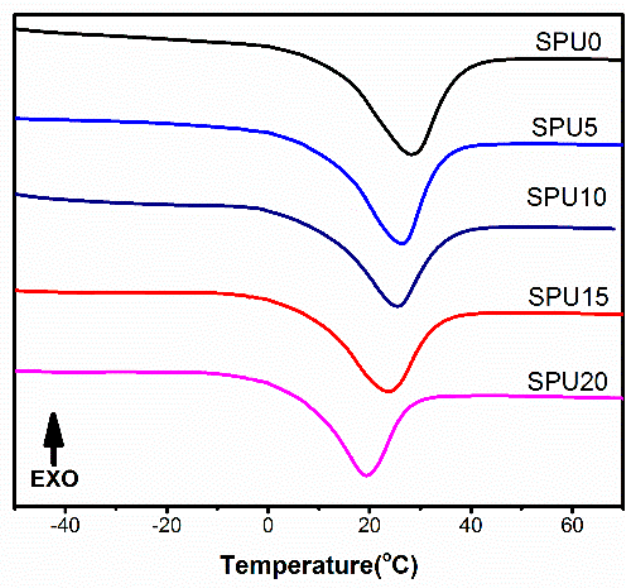

(b)

Figure 8. DSC thermograms of SPU films with different HDI-T contents: (a) curves of the cooling process; and (b) curves of the second heating process.

Table 2. Crystallization temperature and melting temperature of different SPU films.

\begin{tabular}{cccccc}
\hline Sample & SPU0 & SPU5 & SPU10 & SPU15 & SPU20 \\
\hline Crystallization temperature $\left({ }^{\circ} \mathrm{C}\right)$ & -22.4 & -23.9 & -25.4 & -31.1 & -31.5 \\
Melting temperature $\left({ }^{\circ} \mathrm{C}\right)$ & 29.1 & 26.3 & 25.7 & 23.8 & 19.8 \\
\hline
\end{tabular}

\subsection{X-ray Diffraction Analysis}

X-ray patterns of the SPU with different HDI-T contents are shown in Figure 9. All the diffractograms were similar and exhibited a broad diffraction halo around $22^{\circ}$. Moreover, the diffraction peak became weaker and broader with increasing HDI-T content, implying that the crystallinity of SPU films gradually decreased with increasing HDI-T content. The hydrolysis and condensation reaction of alkoxy silane in HDI-T and NBAPTS formed a Si-O-Si cross-linked network structure, which restricted the movement and ordered arrangement of chain segments, decreased the regularity of soft-segments, and therefore led to a decrease in the crystallinity of soft-segments [23,24,34].

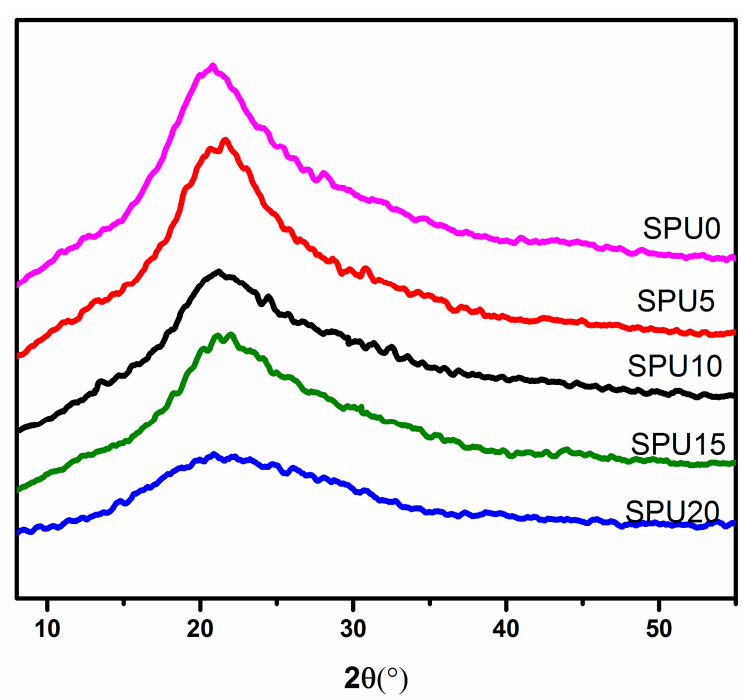

Figure 9. X-ray diffractograms of SPU films containing different HDI-T contents. 


\subsection{SEM Analysis of Surface Morphologies}

Figure 10 shows the morphologies of the surfaces of the SPU films by SEM. The surface of the SPU0 was rough and contained white spots which might be siloxane particles. As the HDI-T content increased, the white spots vanished and the surface of the film became smoother. The surface of the SPU20 film was smooth and was significantly different from the films containing low HDI-T contents. It is known that microstructures of PU block copolymers can be affected by the chemical compositions and lengths of the blocks, and the miscibility between hard and soft segments [38,39]. In this work, the hard segments were composed of urethane and urea groups, and the soft ones polyester carbonyls and $\mathrm{Si}-\mathrm{O}-\mathrm{Si}$ chains. Moreover, the soft segments were the matrix and the hard ones were dispersed in it. The surfaces of the films of such materials could range from strongly phase separated to nearly homogeneous, depending on the miscibility between their soft and hard segments.
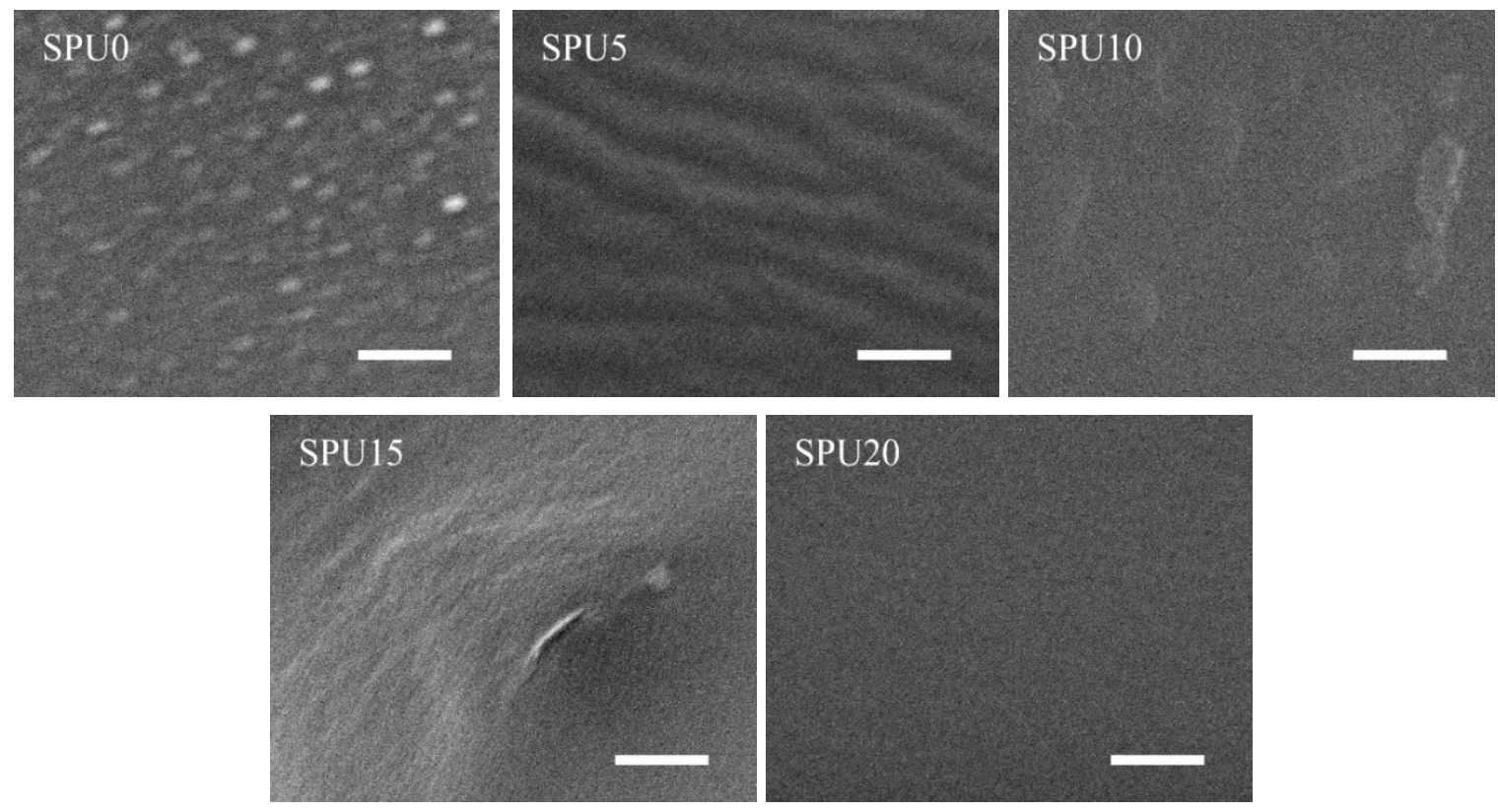

Figure 10. SEM micrographs of the surfaces of SPU films (scale bar $=10 \mu \mathrm{m})$.

The EDS analysis was performed to identify the presence of atoms in the samples at a depth of 100-1000 nm from the surfaces. The expected elements (C, O and Si) can be observed in Figure 11 and Table 3. The percentage of Si element on the surface increased from $0.33 \%$ (SPU0) to $0.89 \%$ (SPU20) with increasing HDI-T content and consequently crosslinking degree. The theoretical and experimental results of EDS for the content of Si matched fairly well.

Table 3. Theoretical and experimental EDS results of SPU films.

\begin{tabular}{ccc}
\hline \multirow{2}{*}{ Sample } & \multicolumn{2}{c}{ Si Concentration/\% } \\
\cline { 2 - 3 } & Theoretical & Experimental \\
\hline SPU0 & 0.40 & 0.33 \\
SPU5 & 0.45 & 0.43 \\
SPU10 & 0.50 & 0.59 \\
SPU15 & 0.55 & 0.68 \\
SPU20 & 0.60 & 0.89 \\
\hline
\end{tabular}




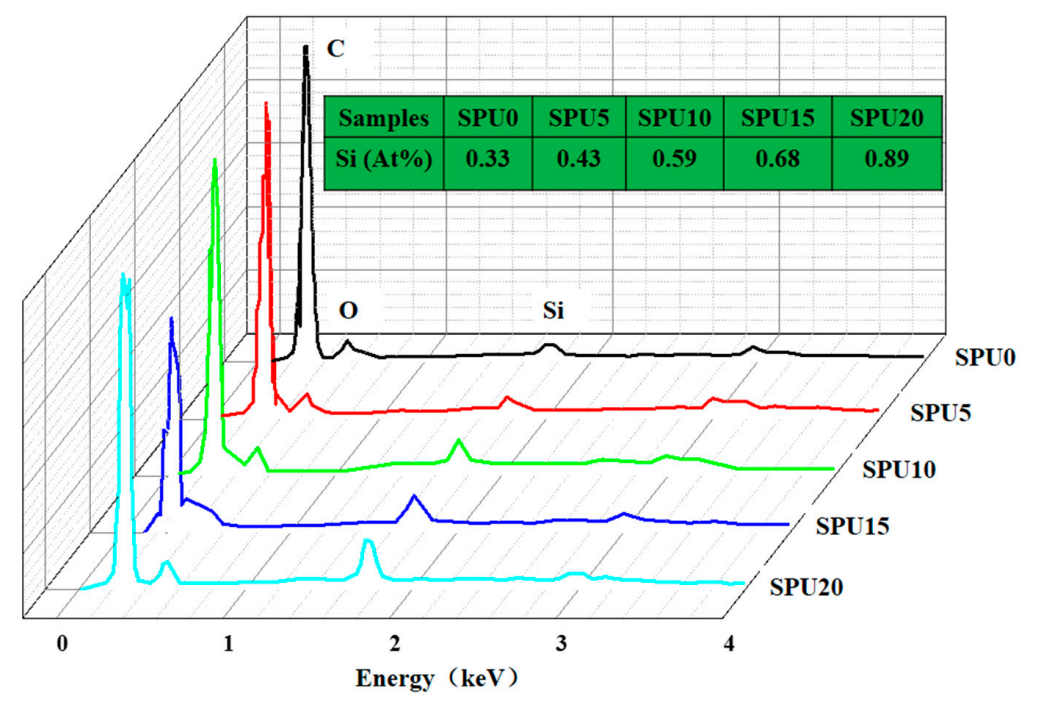

Figure 11. EDS analysis of different SPU films surfaces.

\subsection{Thermal Properties of SPU Films}

Figure 12 shows the TGA and DTG curves of all SPU hybrid films. They all showed two-stage decomposition temperatures. The slight weight loss up to $250{ }^{\circ} \mathrm{C}$ was due to the evaporation of residual moisture and the presence of organic solvents in the films [40]. The weight loss between 250 and $350{ }^{\circ} \mathrm{C}$ was attributed to the dissociation of urethane bonds to form isocyanates, alcohol and amines [41]. The degradation above $400{ }^{\circ} \mathrm{C}$ was mainly due to the scission of the cross-linked structure. The major decomposition product was $\mathrm{SiO}_{2}$. The DTG curves of the SPUs shifted slightly to a lower temperature with an increase in HDI-T content, which was slightly different from some of the research works reported in the literature [39]. Two factors might be responsible for this phenomenon. On the one hand, as HDI-T content increased, the gel content of SPU increased as shown in Figure 13. That was beneficial for the thermal stability. On the other hand, the content of $\mathrm{C}-\mathrm{N}$ bond increased with increasing HDI-T content. However, the bond energy of C-N $\left(305 \mathrm{~kJ} \cdot \mathrm{mol}^{-1}\right)$ was lower than those of $\mathrm{C}-\mathrm{C}\left(346.9 \mathrm{~kJ} \cdot \mathrm{mol}^{-1}\right)$ and $\mathrm{C}-\mathrm{H}\left(414 \mathrm{~kJ} \cdot \mathrm{mol}^{-1}\right)$. That was unfavorable for the thermal stability. Therefore, the thermal stability of the SPU films was a trade-off between these two opposite factors.

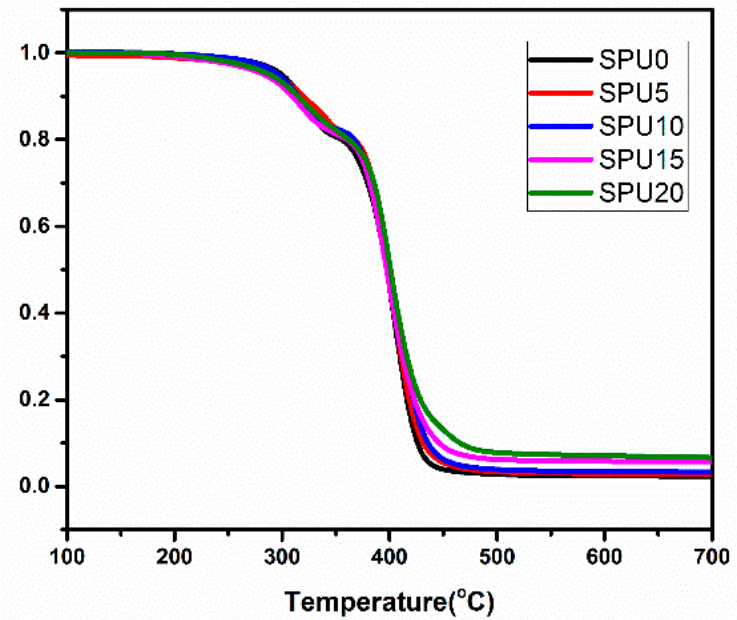

(a)

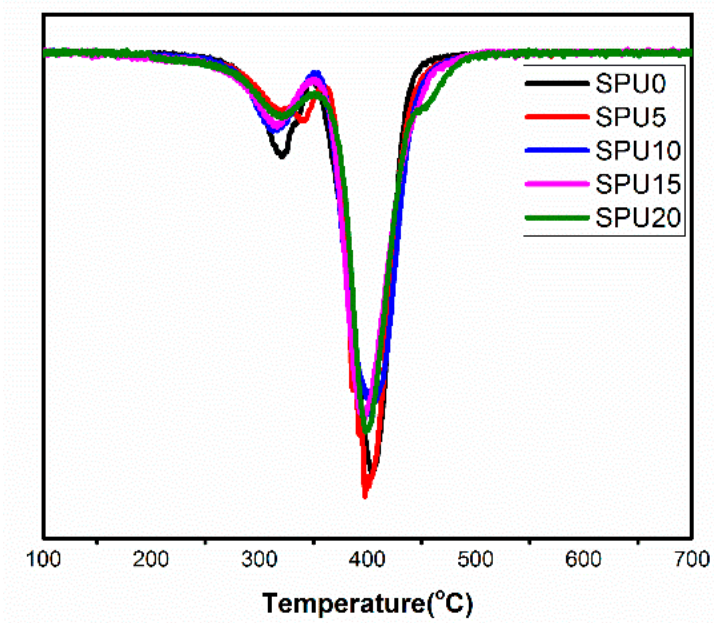

(b)

Figure 12. TGA (a) and DTG (b) curves of the SPU film samples. 


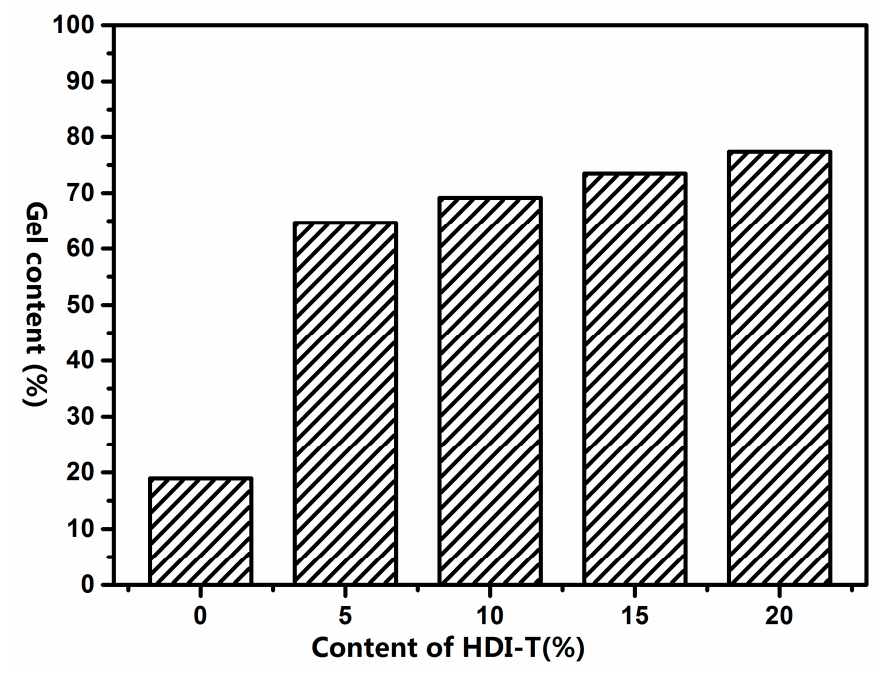

Figure 13. Gel contents of SPU films.

\subsection{Mechanical Properties of SPU Films}

Figure 14 shows that the tensile strength of the SPU films increased with increasing HDI-T content, whereas their elongation at break showed an opposite trend because of an increase in the crosslinking degree of SPU films with the formation of Si-O-Si linkage through the hydrolysis and condensation process. Table 4 summarizes the Young's modulus, tensile strength, elongation at break and pencil hardness values as a function of HDI-T content. When HDI-T content was increased from 0 to $20 \mathrm{~mol} \%$, the Young's modulus and tensile strength were increased from $0.41 \mathrm{MPa}$ to $1.77 \mathrm{MPa}$ and from $0.15 \mathrm{MPa}$ to $0.55 \mathrm{MPa}$, respectively. Meanwhile, the elongation at break decreased from $1019.7 \%$ to $471.4 \%$, suggesting an increased brittleness. All those changes resulted from the increased crosslinking degree. The crosslinking reduced the mobility of the chains during tensile deformation and consequently increased their mechanical properties [42,43]. The hardness increased from HB to $2 \mathrm{H}$ with increasing HDI-T content.

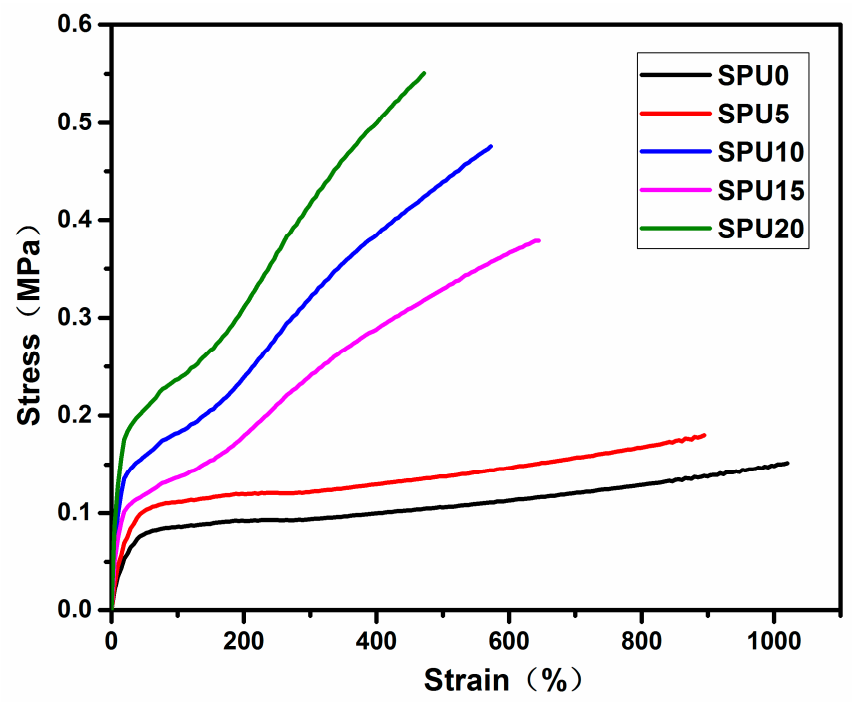

Figure 14. Tensile stress-strain curves of SPU with different HDI-T contents. 
Table 4. Mechanical properties of SPU films with different HDI-T contents.

\begin{tabular}{ccccc}
\hline $\begin{array}{c}\text { HDI-T Content } \\
(\%)\end{array}$ & $\begin{array}{c}\text { Young's Modulus } \\
\text { (MPa) }\end{array}$ & $\begin{array}{c}\text { Tensile Strength } \\
\text { (MPa) }\end{array}$ & $\begin{array}{c}\text { Elongation at } \\
\text { Break (\%) }\end{array}$ & $\begin{array}{c}\text { Pencil } \\
\text { Hardness }\end{array}$ \\
\hline 0 & 0.41 & 0.15 & 1019.7 & $\mathrm{HB}$ \\
5 & 0.53 & 0.18 & 894.6 & $\mathrm{H}$ \\
10 & 1.02 & 0.38 & 644.5 & $2 \mathrm{H}$ \\
15 & 1.36 & 0.48 & 572.3 & $2 \mathrm{H}$ \\
20 & 1.77 & 0.55 & 471.4 & $2 \mathrm{H}$ \\
\hline
\end{tabular}

\subsection{Surface Property and Water Absorption of SPU Films}

The contact angle of water test was used to characterize the surface properties of SPU films. The results are shown in Figure 15. As the HDI-T content increased, the contact angle of water on the SPU film increased. It was $66.5^{\circ}, 71.5^{\circ}, 79.2^{\circ}, 81.2^{\circ}$ and $86.5^{\circ}$ for SPU0, SPU5, SPU10, SPU15 and SPU20, respectively, indicating an obvious improvement in hydrophobicity of the SPU films. The results indicated that the incorporation of alkoxysilane reduced the surface free energy of the SPU films because of the migration of Si atoms with a low polarity to the surfaces of the SPU films [44]. Therefore, the wettability of the SPU films decreased and their hydrophobicity increased with increasing alkoxysilane content. This phenomenon agreed with the results reported in the literature [45-47].

\section{SPU0 SPU5 $\quad$ SPU15}

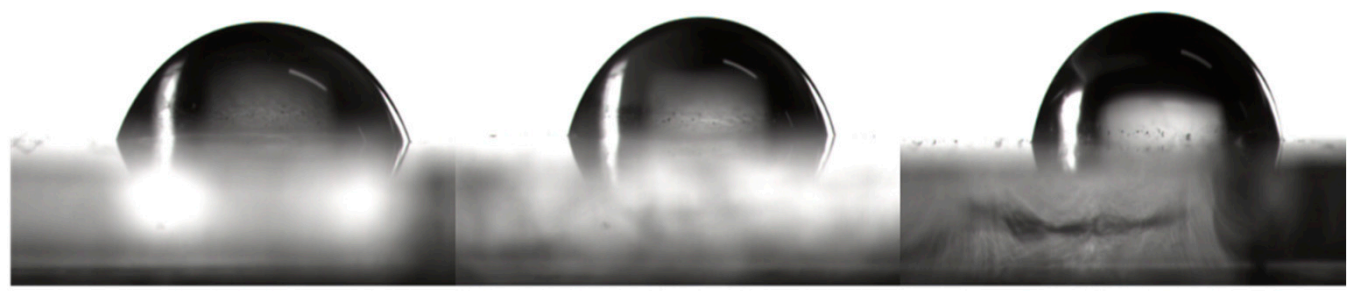

SPU10

SPU20

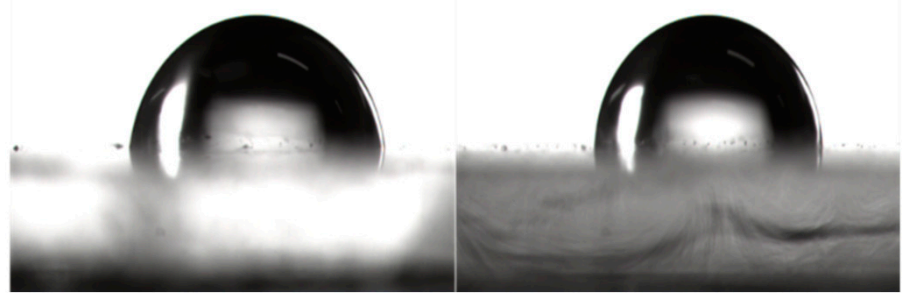

Figure 15. Contacts angle of water on SPU films.

In parallel with the improved surface hydrophobicity with increasing HDI-T content from $0 \%$ to $20 \%$, the water absorption of the SPU films after seven days decreased from $27.2 \%$ to $7.6 \%$, as shown in Figure 16. This indicates that the incorporation of HDI-T in SPU improved their water resistance. This may be ascribed to the formation of a hydrophobic layer of $\mathrm{Si}-\mathrm{O}-\mathrm{Si}$ chains enriched on the surface of SPU film and that of a crosslinked siloxane network structure, both of which prevent water molecules from getting into and diffusing through the film. 


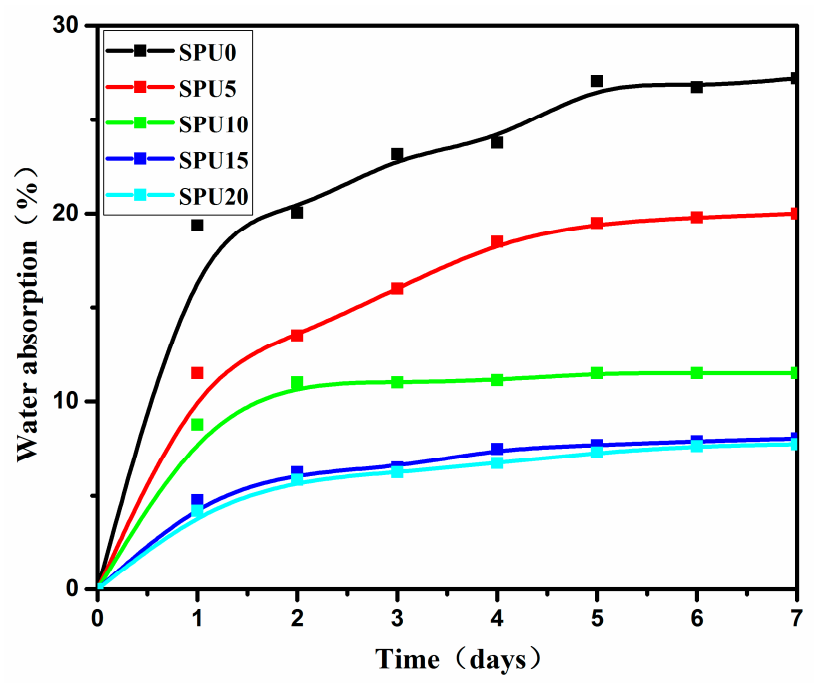

Figure 16. Water absorption of SPU films as a function of time in days.

\section{Conclusions}

In this study, we synthesized HDI-T and incorporated it into SPU chains. HDI-T content was between 0 and $20 \mathrm{~mol} \%$. FT-IR, XPS and XRD results showed successful incorporation of HDI-T into polyurethanes and the formation of Si-O-Si. SEM images exhibited a much smoother surface and EDS test found the Si element content increased as the increase of HDI-T content, DSC demonstrated that both crystallization temperature and melting temperature moved to a lower point as a result of the incorporation of HDI-T. The resulted SPU coating films exhibited an increased surface hydrophobicity and decreased water adsorption. Meanwhile, the Young's modulus, tensile strength and pencil hardness of the films were also improved with increasing HDI-T content, but their elongation at break decreased. The thermal stability of the SPU films became poorer with the incorporation of more C-N bond as a result of an increase in HDI-T content. This study provided a new effective way to prepare SPU coating materials with different performances.

Author Contributions: This research was done by Hui Zhao and Da Huang, Tao Jiang and Qun-Chao Zhang guided it, Hui Zhao finished this paper with the help of Tong-Hui Hao, and it was revised by Guo-Hua Hu.

Conflicts of Interest: The authors declare no conflict of interest.

\section{References}

1. Zhang, Q.; Hu, J.; Gong, S. Preparation and characterization of aqueous polyurethane dispersions with well-defined soft segments. J. Appl. Polym. Sci. 2011, 122, 3064-3070. [CrossRef]

2. Jóźwiak, A.B.; Kielty, C.M.; Black, R.A. Surface functionalization of polyurethane for the immobilization of bioactive moieties on tissue scaffolds. J. Mater. Chem. 2008, 18, 2240-2248. [CrossRef]

3. Osman, M.A.; Mittal, V.; Morbidelli, M.; Suter, U.W. Polyurethane adhesive nanocomposites as gas permeation barrier. Macromolecules 2003, 36, 9851-9858. [CrossRef]

4. Ihata, O.; Kayaki, Y.; Ikariya, T. Synthesis of Thermoresponsive Polyurethane from 2-Methylaziridine and Supercritical Carbon Dioxide. Angew. Chem. Int. Ed. 2004, 43, 717-719. [CrossRef] [PubMed]

5. You, M.; Zhang, X.X.; Wang, J.P.; Wang, X.C. Polyurethane foam containing microencapsulated phase-change materials with styrene-divinybenzene co-polymer shells. J. Mater. Sci. 2009, 44, 3141-3147. [CrossRef]

6. Li, Y.-J.; Tomita, T.; Tanda, K.; Nakaya, T. Synthesis and hemocompatibility evaluation of novel segmented polyurethanes with phosphatidylcholine polar headgroups. Chem. Mater. 1998, 10, 1596-1603. [CrossRef]

7. Petrović, Z.S.; Ferguson, J. Polyurethane elastomers. Prog. Polym. Sci. 1991, 16, 695-836. [CrossRef]

8. Vlad, S.; Spiridon, I.; Grigoras, C.V.; Drobota, M.; Nistor, A. Thermal, mechanical and wettability properties of some branched polyetherurethane elastomers. e-Polymers 2013, 9, 1618-7229. [CrossRef] 
9. Vlad, S.; Oprea, S. Effect of polyols on the physico-mechanical properties of some polyurethanes. J. Optoelectron. Adv. Mater. 2007, 9, 994-999.

10. Buma, P.; Ramrattan, N.V.; van Tienen, T.G.; Veth, R.P. Tissue engineering of the meniscus. Biomaterials 2004, 25, 1523-1532. [CrossRef]

11. Yeganeh, H.; Moeini, H.R. Novel Polyurethane Electrical Insulator Coatings Based on Amide-Ester-Ether Polyols Derived from Castor Oil and Re-cycled Poly(ethylene terphthalate). High Perform. Polym. 2007, 19, 113-126. [CrossRef]

12. Zhang, C.; Zhang, X.; Dai, J.; Bai, C. Synthesis and properties of PDMS modified waterborne polyurethane-acrylic hybrid emulsion by solvent-free method. Prog. Organ. Coat. 2008, 63, 238-244. [CrossRef]

13. Malay, O.; Oguz, O.; Kosak, C.; Yilgor, E.; Yilgor, I.; Menceloglu, Y.Z. Polyurethaneurea-silica nanocomposites: Preparation and investigation of the structure-property behavior. Polymer 2013, 54, 5310-5320. [CrossRef]

14. Fan, Q.; Fang, J.; Chen, Q.; Yu, X. Synthesis and properties of polyurethane modified with aminoethylaminopropyl poly (dimethyl siloxane). J. Appl. Polym. Sci. 1999, 74, 2552-2558. [CrossRef]

15. Okkema, A.; Fabrizius, D.; Grasel, T.; Cooper, S.; Zdrahala, R. Bulk, surface and blood-contacting properties of polyether polyurethanes modified with polydimetnylsiloxane macroglycols. Biomaterials 1989, 10, $23-32$. [CrossRef]

16. Jeon, H.T.; Jang, M.K.; Kim, B.K.; Kim, K.H. Synthesis and characterizations of waterborne polyurethane-silica hybrids using sol-gel process. Colloids Surf. A Physicochem. Eng. Asp. 2007, 302, 559-567. [CrossRef]

17. Bai, C.; Zhang, X.; Dai, J.; Wang, J. Synthesis of UV crosslinkable waterborne siloxane-polyurethane dispersion PDMS-PEDA-PU and the properties of the films. J. Coat. Technol. Res. 2008, 5, 251-257. [CrossRef]

18. Subramani, S.; Lee, J.Y.; Choi, S.W.; Kim, J.H. Waterborne trifunctionalsilane-terminated polyurethane nanocomposite with silane-modified clay. J. Polym. Sci. Part B Polym. Phys. 2007, 45, 2747-2761. [CrossRef]

19. Nanda, A.K.; Wicks, D.A. The influence of the ionic concentration, concentration of the polymer, degree of neutralization and chain extension on aqueous polyurethane dispersions prepared by the acetone process. Polymer 2006, 47, 1805-1811. [CrossRef]

20. Kim, C.; Kim, B.; Jeong, H. Aqueous dispersion of polyurethane ionomers from hexamethylene diisocyanate and trimellitic anhydride. Colloid Polym. Sci. 1991, 269, 895-900. [CrossRef]

21. Xu, J.; Shi, W.; Pang, W. Synthesis and shape memory effects of Si-O-Si cross-linked hybrid polyurethanes. Polymer 2006, 47, 457-465. [CrossRef]

22. Yeh, J.-M.; Yao, C.-T.; Hsieh, C.-F.; Yang, H.-C.; Wu, C.-P. Preparation and properties of amino-terminated anionic waterborne-polyurethane-silica hybrid materials through a sol-gel process in the absence of an external catalyst. Eur. Polym. J. 2008, 44, 2777-2783. [CrossRef]

23. Subramani, S.; Lee, J.; Cheong, I.; Kim, J. Synthesis and characterization of water-borne crosslinked silylated polyurethane dispersions. J. Appl. Polym. Sci. 2005, 98, 620-631. [CrossRef]

24. Fei, G.; Shen, Y.; Wang, H.; Shen, Y. Effects of polydimethylsiloxane concentration on properties of polyurethane/polydimethylsiloxane hybrid dispersions. J. Appl. Polym. Sci. 2006, 102, 5538-5544. [CrossRef]

25. Jaisankar, S.N.; Ramalingam, S.; Subramani, H.; Mohan, R.; Saravanan, P.; Samanta, D.; Mandal, A.B. Cloisite-g-Methacrylic acid copolymer nanocomposites by graft from method for leather processing. Indust. Eng. Chem. Res. 2013, 52, 1379-1387. [CrossRef]

26. Hu, Y.; Samanta, D.; Parelkar, S.S.; Hong, S.W.; Wang, Q.; Russell, T.P.; Emrick, T. Ferritin-polymer conjugates: Grafting chemistry and integration into nanoscale assemblies. Adv. Funct. Mater. 2010, 20, 3603-3612. [CrossRef]

27. Ghosh, S.; Maity, S.; Jana, T. Polybenzimidazole/silica nanocomposites: Organic-inorganic hybrid membranes for PEM fuel cell. J. Mater. Chem. 2011, 21, 14897-14906. [CrossRef]

28. Meera, K.M.S.; Sankar, R.M.; Murali, A.; Jaisankar, S.N.; Mandal, A.B. Sol-gel network silica/modified montmorillonite clay hybrid nanocomposites for hydrophobic surface coatings. Colloids Surf. B Biointerfaces 2012, 90, 204-210. [CrossRef] [PubMed]

29. Dahmouche, K.; Santilli, C.V.; Pulcinelli, S.H.; Craievich, A.F. Small-angle X-ray scattering study of sol-gel-derived siloxane-PEG and siloxane-PPG hybrid materials. J. Phys. Chem. B 1999, 103, 4937-4942. [CrossRef]

30. Sanchez, C.; Julián, B.; Belleville, P.; Popall, M. Applications of hybrid organic-inorganic nanocomposites. J. Mater. Chem. 2005, 15, 3559-3592. [CrossRef] 
31. Lambert, J.B.; Gurusamy-Thangavelu, S.A.; Ma, K. The silicate-mediated formose reaction: Bottom-up synthesis of sugar silicates. Science 2010, 327, 984-986. [CrossRef] [PubMed]

32. Tan, H.; Yang, D.; Xiao, M.; Han, J.; Nie, J. Preparation of silica/polyurethane nanocomposites by UV-induced polymerization from surfaces of silica. J. Appl. Polym. Sci. 2009, 111, 1936-1941. [CrossRef]

33. Sen, P.; Mukherjee, S.; Patra, A.; Bhattacharyya, K. Solvation dynamics of DCM in a DPPC vesicle entrapped in a sodium silicate derived sol-gel matrix. J. Phys. Chem. B 2005, 109, 3319-3323. [CrossRef] [PubMed]

34. Nanda, A.K.; Wicks, D.A.; Madbouly, S.A.; Otaigbe, J.U. Nanostructured polyurethane/POSS hybrid aqueous dispersions prepared by homogeneous solution polymerization. Macromolecules 2006, 39, 7037-7043. [CrossRef]

35. Hao, T.; Liu, X.; Hu, G.H.; Jiang, T.; Zhang, Q. Preparation and characterization of polyurethane/POSS hybrid aqueous dispersions from mono-amino substituted POSS. Polym. Bull. 2016, 1-13. [CrossRef]

36. Meera, K.M.S.; Sankar, R.M.; Jaisankar, S.N.; Mandal, A.B. Physicochemical Studies on Polyurethane/Siloxane Cross-Linked Films for Hydrophobic Surfaces by the Sol-Gel Process. J. Phys. Chem. B 2013, 117, 2682-2694. [CrossRef] [PubMed]

37. Lei, L.; Zhang, Y.; Ou, C.; Xia, Z.; Zhong, L. Synthesis and characterization of waterborne polyurethanes with alkoxy silane groups in the side chains for potential application in waterborne ink. Prog. Organ. Coat. 2016, 92, 85-94. [CrossRef]

38. Pergal, M.V.; Džunuzović, J.V.; Poręba, R.; Ostojić, S.; Radulović, A.; Špírková, M. Microstructure and properties of poly(urethane-siloxane)s based on hyperbranched polyester of the fourth pseudo generation. Prog. Organ. Coat. 2013, 76, 743-756. [CrossRef]

39. Zhou, H.; Wang, H.; Tian, X.; Zheng, K.; Cheng, Q. Effect of 3-Aminopropyltriethoxysilane on polycarbonate based waterborne polyurethane transparent coatings. Prog. Organ. Coat. 2014, 77, 1073-1078. [CrossRef]

40. Fu, H.; Wang, Y.; Li, X.; Chen, W. Synthesis of vegetable oil-based waterborne polyurethane/silver-halloysite antibacterial nanocomposites. Compos. Sci. Technol. 2016, 126, 86-93. [CrossRef]

41. Petrović, Z.S.; Yang, L.; Zlatanić, A.; Zhang, W.; Javni, I. Network structure and properties of polyurethanes from soybean oil. J. Appl. Polym. Sci. 2007, 105, 2717-2727. [CrossRef]

42. Allauddin, S.; Narayan, R.; Raju, K.V.S.N. Synthesis and Properties of Alkoxysilane Castor Oil and Their Polyurethane/Urea-Silica Hybrid Coating Films. ACS Sustain. Chem. Eng. 2013, 1, 910-918. [CrossRef]

43. Khan, F.; Kwek, D.; Kronfli, E.; Ahmad, S. Crosslinking of ethylene-propylene (-diene) terpolymer elastomer initiated by an excimer laser. Polym. Degrad. Stab. 2007, 92, 1640-1644. [CrossRef]

44. Jiang, L.; Chen, Y.L.; Hu, C.P. Polyurethaneurea aqueous dispersions prepared with diethyltoluenediamine as chain extender. J. Coat. Technol. Res. 2007, 4, 59-66. [CrossRef]

45. Chang, W.-Y.; Pan, Y.-W.; Chuang, C.-N.; Guo, J.-J.; Chen, S.-H.; Wang, C.-K.; Hsieh, K.-H. Fabrication and characterization of waterborne polyurethane (WPU) with aluminum trihydroxide (ATH) and mica as flame retardants. J. Polym. Res. 2015, 22, 1-9. [CrossRef]

46. Niu, Z.; Bian, F. Synthesis and characterization of multiple cross-linking UV-curable waterborne polyurethane dispersions. Iran. Polym. J. 2012, 21, 221-228. [CrossRef]

47. Jiang, H.; Zheng, Z.; Song, W.; Li, Z.; Wang, X. Alkoxysilane functionalized polyurethane/polysiloxane copolymers: Synthesis and the effect of end-capping agent. Polym. Bull. 2007, 59, 53-63. [CrossRef]

(c) 2017 by the authors. Licensee MDPI, Basel, Switzerland. This article is an open access article distributed under the terms and conditions of the Creative Commons Attribution (CC BY) license (http:/ / creativecommons.org/licenses/by/4.0/). 